\title{
The Relevance of Sexual Biographies in Individuals Convicted of Child Sexual Abuse Offenses for the Development of Pedosexual Interests and Sexual Recidivism
}

\author{
Lisanne Breiling $^{\mathrm{a}}$, Martin Rettenberger ${ }^{\mathrm{abc}}$, Daniel Turner ${ }^{\mathrm{d}}$ \\ [a] Centre for Criminology (Kriminologische Zentralstelle - KrimZ), Wiesbaden, Germany. [b] Johannes Gutenberg \\ University Mainz, Mainz, Germany. [c] Federal Evaluation Centre for Violent and Sexual Offenders, Austrian Prison \\ System, Vienna, Austria. [d] Department of Psychiatry and Psychotherapy, University Medical Center Mainz, Mainz, \\ Germany.
}

Sexual Offending: Theory, Research, and Prevention, 2020, Vol. 15(1), Article e3711, https://doi.org/10.5964/sotrap.3711

Received: 2020-01-17 • Accepted: 2020-04-24 • Published (VoR): 2020-07-22

Handling Editor: L. Maaike Helmus, Simon Fraser University, Burnaby, BC, Canada

Corresponding Author: Lisanne Breiling, Centre for Criminology (Kriminologische Zentralstelle - KrimZ), Viktoriastraße 35, D-65189 Wiesbaden, Germany. E-mail: 1.breiling@krimz.de

\begin{abstract}
In the literature concerning the etiology of pedosexual interests, the potential role of early sexual experiences in childhood and adolescence has been discussed. Several studies demonstrated a link between own sexually abusive experiences in childhood and sexual offending later in life which tends to be even stronger for pedosexual offenders. Furthermore, some findings indicate associations between other developmental factors and deviant sexual interests in adulthood. For the present study, sexual biographical data of $\mathrm{N}=223$ imprisoned men convicted of sexual offenses against children from Austria was analyzed to retrospectively examine whether own sexually abusive experiences and non-abusive forms of early sexual experiences and behaviors are linked to subsequent pedosexual interests and to sexual recidivism. Previous findings concerning the link between own sexually abusive experiences during childhood and subsequent pedosexual interests could partly be replicated. Furthermore, early masturbation behavior characteristics as well as nonabusive prepubescent sexual experiences were linked to indicators of pedosexual interests and also to sexual recidivism. Exclusively pedophilic men showed the strongest accumulation of early sexual experiences and behaviors. Implications of the findings for theory and risk assessment are discussed.
\end{abstract}

\section{Keywords}

sexual offender, child molester, child abuse, pedophilia, risk assessment, sexual reoffending, recidivism 


\section{Highlights}

- Among men convicted of child sexual abuse offenses, sexually abusive experiences during childhood are related to different measures of pedosexual interests during adulthood.

- Non-abusive prepubescent sexual experiences are related to pedosexual interests later in life.

- Men diagnosed with an exclusive pedophilic disorder show the strongest accumulation of early sexual behavior and experiences.

- An accumulation of early sexual behavior and experiences significantly predicts sexual recidivism.

In the course of discussing the origins of sexual offending, the role of deviant sexual interests is most often the focus of attention. Indeed, research has identified deviant sexual interests as an important factor in predicting recidivism in samples of individuals convicted of sexual offenses (Hanson \& Bussière, 1998; Hanson \& Morton-Bourgon, 2004); thus, finding precursors of specific paraphilic interests and behaviors is of importance in helping to prevent sexual offenses. Pedophilic sexual interests are probably the most discussed paraphilic interests in forensic contexts, probably due to their-supposed and actual-relevance in the context of child sexual abuse (CSA).

A pedophilic sexual interest is defined as a sexual preference for prepubescent children (Seto, 2008) and is manifested in "recurrent, intense sexually arousing fantasies, sexual urges, or behaviors involving sexual activity with a prepubescent child or children" (American Psychiatric Association, 2013). In order to diagnose a pedophilic disorder according to the fifth edition of the Diagnostic and Statistical Manual of Mental Disorders (DSM-5; American Psychiatric Association, 2013) the individual must have acted out their pedophilic sexual desires or has to experience significant distress. Furthermore, the DSM-5 suggests a specification of the potential exclusivity of pedosexual interests. Men with an exclusive pedophilic disorder are only attracted to children whereas men with a non-exclusive pedophilic disorder are also sexually attracted to adults. This has also practical implications. For instance, only an exclusive pedophilic sexual disorder is significantly linked to sexual reoffending (Eher et al., 2010, 2015) and it is positively linked to sexual compulsivity (McPhail et al., 2018).

Estimating the prevalence of pedophilic sexual interests in the general population is difficult. In a recent representative online survey with a sample of nearly 9,000 men living in Germany, $4.1 \%$ reported about sexual fantasies involving prepubescent children and $0.1 \%$ reported a pedophilic sexual preference (Dombert et al., 2016). Other studies have found prevalence rates for pedophilic sexual fantasies between $1.1 \%$ and $6.0 \%$ and between $0.4 \%$ and $3.8 \%$ for pedophilic sexual behaviors in the general male population (Ahlers et al., 2011; Baur et al., 2016; Castellini et al., 2018; Joyal \& Carpentier, 2017). 
Taking the existing studies into account, Seto (2018) suggests a "guesstimate" of $1 \%$ for a pedosexual preference in the general male population (for a review, see Seto, 2018, p. 22).

The prevalence of pedophilic sexual interests in forensic samples has been investigated more extensively. In samples of men convicted of CSA offenses, the rate of those with pedophilic sexual interests varies between $30 \%$ and $70 \%$, whereby the precise prevalence rate usually depends on sample characteristics as well as the assessment method (see Eher, 2016). In a recent cross-sectional study (Eher et al., 2019) on the prevalence of mental disorders in a large sample of sexual offenders $(N=1,511), 67.1 \%$ of those individuals convicted because of CSA offenses were diagnosed with a pedophilic disorder and $14.0 \%$ of them received an exclusive pedophilic disorder diagnosis.

The above-mentioned findings reveal the important but sometimes neglected fact that not every individual convicted of CSA has pedosexual interests; nor does every person with pedosexual interests become a sexual offender. This is contrary to public discussions, where the terms pedophile/pedosexual and CSA are often confused and are usually used interchangeably. In their extensive population-based survey, Dombert et al. (2016) found that $56.1 \%$ of those who reported sexual fantasies involving children did not report any pedosexual behavior (i.e., sexual contact with children or consumption of child pornography). However, the comparatively high prevalence in forensic samples as well as the strong and constant public interest requires and justifies a scientifically substantiated examination of that topic; and since paraphilias turned out to be among the most relevant factors in predicting sexual reoffending (Eher et al., 2015; Hanson \& Bussière, 1998), sexual interests in children remain an important factor to consider in the assessment of individuals convicted of sexual offenses.

The etiology of pedosexual interests is still far away from being unequivocally clarified but multiple possible influencing factors have been discussed and examined, involving genetics (e.g., Blanchard et al., 2007), structural brain anomalies (e.g., Cantor et al., 2008; Schiltz et al., 2007), or stressful life events and social learning (e.g., Jespersen, Lalumière, \& Seto, 2009).

Concerning the latter factor, various theories propose that early sexual developmental experiences (or the lack of adequate experiences) may play a substantial role within the etiology of deviant sexual interests and behaviors (e.g., Laws \& Marshall, 1990; Marshall \& Barbaree, 1990). One sexual biographical factor which has been examined extensively stems from the so-called abused-abuser hypothesis which postulates that sexually abused children, especially boys, have a higher risk of committing sexual offenses themselves later in life (e.g., Garland \& Dougher, 1990; Marshall \& Marshall, 2016; Seto, 2008).

Empirical evidence for the abused-abuser hypothesis comes from multiple studies that found higher rates of own sexually abusive experiences during childhood among individuals who have committed sexual offenses against children compared to persons who have not committed sexually motivated offenses or persons who have sexually offended against adults (Jespersen et al., 2009; Seto \& Lalumière, 2010; Whitaker et al., 
2008). Furthermore, there seems to be a specific link in participants who are categorized as being pedophilic: persons who reported being sexually abused in childhood show more indicators of pedosexual interests compared to participants who did not report having been abused as a child (Becker et al., 1992; Craissati et al., 2002; Fedoroff \& Pinkus, 1996; Freund et al., 1990; Hunter \& Becker, 1994; Lee et al., 2002). For example, Nunes et al. (2013) showed that in a sample of 462 male persons convicted of CSA those who had been sexually abused before the age of 16 showed more indicators of pedosexual interests than those who had not been abused.

There is considerably less research though, that focuses on other sexual experiences or behaviors as a possible origin of pedosexual interests. However, based on the mechanisms of model learning and conditioning, non-abusive forms of early sexual experiences or behavior could be predictive for pedosexual interests as well (e.g., Burton, 2003). Concerning non-abusive sexual developmental factors, Santtila et al. (2010) found that $4.3 \%$ of those individuals from the general population who had engaged in any sexual interaction with other children in childhood reported sexual interests in children during adulthood whereas none of those who have had no such interactions did. Furthermore, early exposure to pornography also seems to be associated with self-reported pedosexual interests during adulthood (Wurtele et al., 2014).

One factor that has been repeatedly discussed and examined as a potential correlate of pedosexual interests is an increased sex drive. Sex drive refers to the strength of an individual's motivation to seek for or to engage in sexual activities (for a review, see Baumeister et al., 2001). Pedophilic and hypersexual disorders-as a possible clinical manifestation of a high sex drive-frequently co-occur (Kafka, 2001). Klein and colleagues (2015) found a small but significant relationship between self-reported sexual fantasies involving children and sex drive in a population-based sample of more than 8,000 men living in Germany. Moreover, a recent study found a relationship between an early age at first masturbation and a sexual interest in children in adulthood (Wurtele et al., 2018). Masturbation behavior has been conceptualized as one possible manifestation of sex drive (e.g., Spector et al., 1996) and has the advantage of its independence from experience with sexual partners.

Those above-mentioned findings raise the question whether or not pedophilic men show signs of a high sex drive already during their childhood or puberty and whether or not pedosexual interests could be associated with an early onset of sexual behavior (Wurtele et al., 2018).

\section{Current Study}

At first the present study aimed at replicating previous research concerning the relationship between own sexually abusive experiences and indicators of pedosexual interests later in life among men convicted of CSA-related offenses. Secondly, we aimed at extending previous findings by examining the potential role of other early non-abusive sexuali- 
ty-related experiences in childhood with a focus on high sex drive for the prediction of subsequent pedosexual interests.

Assuming that, compared to a non-exclusive pedophilic disorder, an exclusive pedophilic disorder represents a particularly strong and clinically relevant manifestation of pedosexual interests, it was expected that men diagnosed with an exclusive pedophilic disorder would show the highest rate of own sexually abusive experiences during childhood, followed by men diagnosed with a non-exclusive pedophilic disorder. Similar patterns were expected for other forms of sexual experiences. As the present study focused on men convicted of CSA offenses, hypotheses can only be tested for that specific subgroup of men with, if applicable, pedosexual interests, i.e., men who acted on those interests.

Finally, we aimed at investigating the prognostic relevance of the above-mentioned sexual biographical variables assuming that the presence of abusive as well as non-abusive childhood sexual experiences and early or intense masturbation could be related to an increased risk of sexual reoffending. Thus, the incremental predictive accuracy of those variables for the prediction of sexual reoffending beyond a well-established measure of sexual recidivism risk was examined.

\section{Method}

\section{Data Collection}

In Austria, since 2001 imprisoned sexual offenders are evaluated at the Federal Evaluation Centre for Violent and Sexual Offenders (FECVSO), a department under the Austrian Ministry of Justice, for the purpose of planning the correctional scheme during the term of imprisonment (Eher et al., 2012). An initial file-based risk screening determines whether or not the offender should undergo a comprehensive evaluation at the FECVSO (e.g., every person who has been convicted because of at least one extra-familial child sexual abuse will be evaluated). The criteria are met in about $60 \%$ of all individuals convicted and imprisoned because of sexual offenses who are consequently evaluated at the FECSVO. The data gained in that diagnostic process is collected in forensic-sexological reports. Those reports include information about the index offense and, if applicable, previous convictions. They also provide information about previous employment, social environment, and other biographical aspects. Furthermore, they include results of personality and risk assessment as well as information about sexual development including the presence of psychiatric and sexual disorders.

\section{Sample}

For the present study, the data of $N=223$ adult male sexual offenders were analyzed. Those men had been convicted and imprisoned between 2000 and 2008 in Austria be- 
cause of a CSA offense and have subsequently been evaluated at the FECVSO. Parts of the sample were already investigated in former studies (e.g., Turner et al., 2014, 2016). Due to missing data, the sample size varied across the different statistical analyzes, but the respective samples did not differ significantly from the whole sample concerning the outcome of interest.

\section{Measures}

\section{Pedosexual Interests}

The presence of a pedophilic disorder was based on the diagnostic criteria of the DSM-IV-TR (American Psychiatric Association, 2000). All diagnoses were made by an experienced psychologist or a psychiatrist after an extensive psychiatric evaluation. Furthermore, the pedophilic disorder was rated as either exclusive or non-exclusive.

Furthermore, the Screening Scale for Pedophilic Interests (SSPI; Seto \& Lalumière, 2001) was rated retrospectively by Turner et al. (2014), since it was not part of the FECVSO reports. The SSPI can be rated based on file information only. It consists of four dichotomous items: any victim younger than 12 years, any male victims, more than one victim, and any extra-familial victims. The total SSPI scores can range between 0 and 5 (the any male victim item counts double). Previous research demonstrated that in samples of men convicted because of CSA offenses SSPI scores correlate with phallometrically assessed sexual interests in prepubescent children (Seto \& Lalumière, 2001; Seto et al., 2003, 2004) and predict sexual and violent recidivism (Eher et al., 2015; Helmus et al., 2015).

\section{Sexual Biographical Characteristics}

Questions concerning sexual development, behavior and experiences are part of the initial diagnostic process at the FECVSO and are set forth in the forensic reports. For the purpose of the present study we created the following variables: own sexually abusive experiences (below the age of 16), prepubescent non-abusive sexual experiences, age at onset of masturbation (in years), and frequency of masturbation during puberty. In detail prepubescent non-abusive sexual experiences might be sexual play ("doctor games") with other (e.g., neighborhood) children, however, this could also mean kissing and taking each other's clothes off during spin-the-bottle or touching and investigating each other's genitals. Own sexually abusive as well as non-abusive sexual experiences were coded dichotomously (i.e., 0 = absent, 1 = present). The differentiation between sexually abusive and non-abusive experiences was primarily based on the recollections and biographical narratives of the participant which he provided in the course of the report explorations. Frequency of masturbation was assessed on a four-step scale, possible answers being $0=$ never (or very seldom), 1 = occasionally (now and then up to $1-2 x /$ week), $2=$ regularly (at least $2 x$ (week), or $3=$ daily. 
In a further step, a sexual biographical index based on the four sexual biographical variables was computed, representing accumulated early sexual behaviors and (abusive as well as non-abusive) experiences. Due to the ordinal scaling of frequency of masturbation the formation of the index was based on non-parametric distribution values of the variables (i.e., the median). For each person's index value, the frequencies of overstepping the median were calculated and summed up. A value of 4 indicates that the person lay above the median of each of the four sexual biographical variables which represents the maximum accumulation of early sexual behaviors and experiences.

\section{Risk Assessment}

The Static-99 (Hanson \& Thornton, 1999, 2000) is a well-established and validated actuarial risk assessment instrument developed for the application to adult male sexual offenders. It consists of 10 mainly dichotomously coded items (i.e., presence or absence of the risk factor) which assess static demographic information (e.g., age, presence of intimate relationship experiences), information about the index and prior offenses and convictions, and information about the relationship with the victim(s). The item asking about prior sexual offenses is the only one which is rated on a 4-point scale. Thus, the highest total score is 12 indicating the highest recidivism risk. The predictive accuracy for sexual recidivism ranges from moderate (AUC = .66; Ducro \& Pham, 2006) to good (AUC = .76; Sjöstedt \& Långström, 2001). For the present study, the German adaption of the Static-99 was used (Eher et al., 2012; Rettenberger et al., 2010). The instrument's interrater reliability in the investigated sample has already been reported elsewhere (Rettenberger et al., 2010) and can be classified as excellent (Intraclass Correlation Coefficient [ICC] = .98) according to Fleiss (1986). The Static-99 is a regular part of the assessment of the FECSVO, and thus, was assessed prospectively.

Later, Helmus et al. (2012) developed a revised version of the Static-99 with new age weights, the Static-99R. However, a comparison of the original Static-99 and the new Static-99R in a population-based sample of prison-released individuals convicted of sexual offenses from Austria $(N=1,077)$ revealed that the Static-99 (AUC $=.73)$ performed better than the age-corrected Static-99R in predicting sexual recidivism (AUC = .71; Rettenberger et al., 2013). Therefore, the original version, the Static-99, was used for the data analyzed in the present study.

\section{Recidivism Data}

Data on recidivism (defined as a legally valid reconviction) were retrieved from the Federal Central Register of the Austrian Ministry of Internal Affairs. The evaluators of the reconviction data were blind for all other variables, and each new conviction listed in the criminal records was counted as a reoffense. For the present study, sexual reoffending was the outcome of interest, therefore any reconviction due to a sexual offense, contact as well as non-contact, was taken into account. The mean follow-up period after release 
from prison in the total sample $(n=202)$ was $M=5.68$ years $(S D=1.43$, minimum $=3.36$, maximum $=9.37$.

\section{Results}

\section{Clinical and Criminological Sample Characteristics}

The clinical and criminological variables of our sample are shown in Table 1. There was a moderate correlation between both measures of pedosexual interests, i.e., clinical diagnosis and SSPI scores $(n=218, r=.45, p<.001)$. As expected, exclusively pedophilic men had the highest SSPI score $(M=4.22)$, followed by non-exclusive pedophilic participants $(M=2.78)$. Men without a pedophilic disorder had the lowest SSPI scores $(M=1.79)$.

\section{Table 1}

Criminological Characteristics and Descriptive Statistics for the Total Sample $(n=223)$

\begin{tabular}{|c|c|c|c|c|}
\hline Measure & $n$ & $\%$ & $M$ & $S D$ \\
\hline \multicolumn{5}{|l|}{ Criminological characteristics } \\
\hline Age at index offense & 223 & & 37.08 & 11.97 \\
\hline Total number of victims & 221 & & 2.92 & 4.09 \\
\hline Age of youngest victim & 195 & & 8.93 & 3.01 \\
\hline Previous convictions $^{\mathrm{a}}$ & 223 & & 2.97 & 5.50 \\
\hline Previous sexual offenses ${ }^{a}$ & 223 & & 0.45 & 1.36 \\
\hline Pedophilic disorder & 219 & & & \\
\hline No disorder & 119 & 54.3 & & \\
\hline Non-exclusive & 77 & 35.2 & & \\
\hline Exclusive & 23 & 10.5 & & \\
\hline SSPI Scores & 222 & & 2.43 & 1.60 \\
\hline Own sexually abusive experiences & 213 & & & \\
\hline Present & 49 & 23.0 & & \\
\hline Absent & 164 & 77.0 & & \\
\hline Prepubescent sexual experiences & 209 & & & \\
\hline Present & 52 & 24.9 & & \\
\hline Absent & 157 & 75.1 & & \\
\hline Onset of masturbation ${ }^{b}$ & $152^{\mathrm{e}}$ & & 13.60 & 2.27 \\
\hline Frequency of masturbation ${ }^{c}$ & 131 & & & \\
\hline 0 & 19 & 14.5 & & \\
\hline 1 & 57 & 43.5 & & \\
\hline 2 & 35 & 26.7 & & \\
\hline 3 & 20 & 15.3 & & \\
\hline
\end{tabular}




\begin{tabular}{|c|c|c|c|c|}
\hline Measure & $n$ & $\%$ & $M$ & $S D$ \\
\hline Sexual biographical index ${ }^{d}$ & 105 & & 1.53 & 1.16 \\
\hline Static-99 & 200 & & 2.58 & 2.21 \\
\hline Sexual recidivism & 202 & & & \\
\hline Yes & 21 & 10.4 & & \\
\hline No & 181 & 89.6 & & \\
\hline
\end{tabular}

Note. SSPI = Screening Scale of Pedophilic Interests (Seto \& Lalumière, 2001).

${ }^{a}$ Excluding index offense. ${ }^{\mathrm{b}}$ Age in years. ${ }^{\mathrm{c}}$ During puberty $(0=$ never [or very seldom], $1=$ occasionally [now and then up to $1-2 x /$ week]: 2 = regularly [at least $2 x /$ week], or $3=$ daily). ${ }^{\text {II }}$ Index representing accumulation of early sexual behavior and (abusive or non-abusive) experiences. ${ }^{\mathrm{e}} n=8$ men reported they had never masturbated.

\section{Sexual Biographical Variables and Pedophilic Disorder}

To investigate links between the biographical sexual variables and a pedophilic disorder diagnosis, the sample was sorted according to the exclusivity of a pedophilic disorder $(0=$ no disorder, $1=$ non-exclusive disorder, $2=$ exclusive disorder $)$ and Spearman's rank correlation coefficients were calculated (see Table 2).

\section{Table 2}

Spearman's Rank Correlation Coefficients and Frequencies of the Sexual Biographical Variables for the Three Groups Differentiated According Their Pedophilic Disorder Diagnosis

\begin{tabular}{|c|c|c|c|c|c|}
\hline \multirow[b]{3}{*}{ Sexual biographical variable } & \multicolumn{3}{|c|}{ Pedophilic disorder } & & \\
\hline & \multirow{2}{*}{$\begin{array}{c}\begin{array}{c}\text { No pedophilic } \\
\text { disorder }\end{array} \\
n\left(\%^{c}\right) / M(S D)\end{array}$} & \multirow{2}{*}{$\begin{array}{c}\begin{array}{c}\text { Non-exclusive } \\
\text { pedophilic } \\
\text { disorder }\end{array} \\
n\left(\%^{\mathrm{c}}\right) / M(S D)\end{array}$} & \multirow{2}{*}{$\begin{array}{c}\begin{array}{c}\text { Exclusive } \\
\text { pedophilic } \\
\text { disorder }\end{array} \\
n\left(\%^{\mathrm{c}}\right) / M(S D)\end{array}$} & \multicolumn{2}{|c|}{ Effect size } \\
\hline & & & & $r$ & $p$ \\
\hline Own sexually abusive experiences ${ }^{\mathrm{a}}$ & $18(15.5)$ & $19(26.8)$ & $10(45.5)$ & .21 & .002 \\
\hline $\begin{array}{l}\text { Prepubescent non-abusive sexual } \\
\text { experiences }^{\mathrm{a}}\end{array}$ & $18(16.1)$ & $20(28.2)$ & $10(54.5)$ & .25 & $<.001$ \\
\hline Onset of masturbation (in years) & $13.80(1.90)$ & $13.60(2.59)$ & $13.15(2.55)$ & -.05 & .517 \\
\hline Daily masturbation during puberty ${ }^{\mathrm{b}}$ & $8(11.4)$ & $6(13.6)$ & $5(35.7)$ & .12 & .168 \\
\hline Sexual biographical index & $1.32(1.07)$ & $1.49(1.12)$ & $2.50(1.31)$ & .23 & .020 \\
\hline
\end{tabular}

Note. Pedophilic disorder $(0=$ no disorder, $1=$ non-exclusive disorder, $2=$ exclusive disorder $)$; Sexual biographical index $=$ accumulation of early sexual behavior and (abusive or non-abusive) experiences.

${ }^{\mathrm{a}} 0=$ absent, $1=$ present $.{ }^{\mathrm{b}} 0=$ never $($ or very seldom), $1=$ occasionally (now and then up to $1-2 x /$ week), $2=$ regularly (at least $2 x /$ week), or $3=$ daily. ${ }^{~}$ Percentage with present referring experiences in the referring pedophilic disorder group. 
Further pairwise group comparisons revealed significant differences between men with an exclusive pedophilic disorder and men without a pedophilic disorder diagnosis concerning their rate of own sexually abusive experiences, $\chi^{2}(1)=10.25, p=.001, \Phi=.27$, and their rate of prepubescent non-abusive sexual experiences, $\chi^{2}(1)=15.67, p<.001, \Phi$ $=.34$, indicating small effects in both cases (Cohen, 1988). Those two groups also differed significantly concerning their mean sexual biographical index value, $t(63)=3.30 ; p=.002$, $d=0.98$, indicating a large effect (Cohen, 1988). No other group differences reached the intended level of significance (i.e., $\alpha=.017$, due to Bonferroni correction).

\section{Sexual Biographical Variables and SSPI Score}

The associations between the sexual biographical variables and the SSPI score are displayed in Table 3. As expected, the SSPI score showed a significant positive correlation with own sexually abusive experiences, prepubescent sexual experiences, the frequency of masturbation and the biographical index and a significant negative correlation with the age of onset of masturbation.

Table 3

Correlation Coefficients of Sexual Biographical Variables and SSPI Scores (p-Values in Parentheses)

\begin{tabular}{|c|c|c|c|c|c|}
\hline Measure & $\begin{array}{l}\text { Own sexually } \\
\text { abusive } \\
\text { experiences }^{\mathbf{a}}\end{array}$ & $\begin{array}{l}\text { Prepubescent non- } \\
\text { abusive sexual } \\
\text { experiences }^{\mathbf{a}}\end{array}$ & $\begin{array}{c}\text { Onset of } \\
\text { masturbation (in } \\
\text { years) }\end{array}$ & $\begin{array}{l}\text { Frequency of } \\
\text { masturbation }^{b}\end{array}$ & $\begin{array}{c}\text { Sexual } \\
\text { biographical index }\end{array}$ \\
\hline \multirow[t]{2}{*}{ SSPI Scores } & $.14(.042)^{\mathrm{d}}$ & $.24(.001)^{\mathrm{d}}$ & $-.21(.010)^{\mathrm{d}}$ & $.27(.002)^{\mathrm{c}}$ & $.36(<.001)^{\mathrm{d}}$ \\
\hline & $n=212$ & $n=208$ & $n=151$ & $n=130$ & $n=104$ \\
\hline
\end{tabular}

Note. SSPI $=$ Screening Scale of Pedophilic Interests (Seto \& Lalumière, 2001); Pedophilic disorder $(0=$ no disorder, $1=$ non-exclusive disorder, 2 = exclusive disorder); Sexual biographical index = accumulation of early sexual behavior and (abusive or non-abusive) experiences.

${ }^{\mathrm{a}} 0=$ absent, $1=$ present. ${ }^{\mathrm{b}} 0=$ never (or very seldom), $1=$ occasionally (now and then up to $1-2 x /$ week), $2=$ regularly

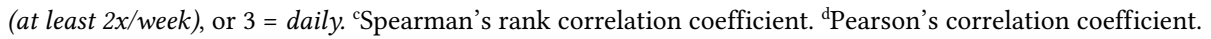

\section{Multivariate Prediction of Pedosexual Interests}

Associations between sexual biographical characteristics and subsequent pedosexual interests were, additionally, tested in multivariate models, in order to take the common variance of the different predictors into account. In the run-up to regression analyses, interrelationships of the predictors were calculated (see Appendix).

\section{Prediction of a Pedophilic Disorder Diagnosis}

An ordinal logistic regression was performed in order to predict the clinical outcome of a pedophilic disorder. The $\chi^{2}$-statistics indicate an improvement in model fit by adding the predictors of interest, $\chi^{2}(4)=12.47, p=.014$. Parameter estimates of the regression model are shown in Table 4. Positive estimates indicate that, as the predictor variable increases, 
there is an increase in the odds of falling at a higher level on the dependent variable. The significant estimate of own sexually abusive experiences indicates that men who reported such experiences have increased odds of having a pedophilic disorder, whereas the other predictors are not significantly linked to the outcome.

Table 4

Ordinal Logistic Regression of Clinically Diagnosed Pedophilic Disorder $(n=102)$

\begin{tabular}{|c|c|c|c|c|c|}
\hline Predictor & $\begin{array}{c}\text { Logit } \\
\text { coefficient }\end{array}$ & $S E$ & Wald & $p$ & $\begin{array}{l}95 \% \mathrm{CI} \text { of } \\
\text { Estimate }\end{array}$ \\
\hline \multicolumn{6}{|l|}{ Threshold } \\
\hline Pedophilic disorder $=0$ & -0.56 & 1.70 & 0.11 & .741 & {$[-3.88,2.76]$} \\
\hline Pedophilic disorder $=1$ & 1.58 & 1.71 & 0.85 & .355 & {$[-1.77,4.92]$} \\
\hline \multicolumn{6}{|l|}{ Location } \\
\hline Own sexually abusive experiences ${ }^{a}$ & 1.25 & 0.46 & 7.43 & .006 & {$[0.35,2.14]$} \\
\hline Prepubescent sexual experiences ${ }^{a}$ & 0.64 & 0.53 & 3.53 & .060 & {$[-0.04,1.77]$} \\
\hline Onset of masturbation (in years) & -0.08 & 0.11 & 0.49 & .484 & {$[-0.29,0.14]$} \\
\hline Frequency of masturbation $^{\mathrm{b}}$ & -0.10 & 0.27 & 0.14 & .713 & {$[-0.64,0.47]$} \\
\hline
\end{tabular}

Note. $\mathrm{CI}=$ Confidence interval. Pedophilic disorder $(0=$ no disorder, $1=$ non-exclusive disorder, $2=$ exclusive disorder). $R^{2}=.14$ (Nagelkerke, 1991).

${ }^{\mathrm{a}} 0=$ absent, $1=$ present. ${ }^{\mathrm{b}} 0=$ never (or very seldom), $1=$ occasionally (now and then up to $1-2 x /$ week), $2=$ regularly (at least $2 x$ week), or $3=$ daily.

\section{Prediction of SSPI Scores}

A multiple linear regression analysis was conducted to predict SSPI scores. As all Variance Inflation Factor (VIF) values were below 10 and mean VIF was 1.24, there was no collinearity in the data, these results are shown in Table 5.

Table 5

Multiple Linear Hierarchical Regression of SSPI Scores $(n=104)$

\begin{tabular}{lccccc}
\hline Predictors & $\boldsymbol{b}$ & $\boldsymbol{S E}_{\boldsymbol{b}}$ & $\boldsymbol{\beta}$ & $\boldsymbol{p}$ & VIF \\
\hline Constant & 3.21 & 1.38 & - & .022 & - \\
Own sexually abusive experiences $^{\mathrm{a}}$ & 0.19 & 0.36 & .05 & .596 & 1.07 \\
Prepubescent sexual experiences $^{\mathrm{a}}$ & 0.47 & 0.38 & .12 & .217 & 1.13 \\
Onset of masturbation (in years) $^{\text {Frequency of masturbation }}{ }^{\mathrm{b}}$ & -0.12 & 0.09 & -.15 & .169 & 1.40 \\
\hline
\end{tabular}

Note. SSPI = Screening Scale of Pedophilic Interests (Seto \& Lalumière, 2001). $R^{2}=.14(p=.005)$.

${ }^{\mathrm{a}} 0=$ absent, $1=$ present. ${ }^{\mathrm{b}} 0=$ never (or very seldom), $1=$ occasionally (now and then up to $1-2 x /$ week), $2=$ regularly (at least $2 x /$ week), or $3=$ daily. 
The amount of declared variance was significant, however, none of the single predictors reached the level of incremental significance.

\section{Prognostic Relevance of Sexual Biographical Characteristics}

It was further analyzed whether the sexual biographical characteristics were linked to sexual recidivism. Men who reported own sexually abusive experiences had sexual reoffending rate of $19.1 \%$, whereas men who did not report such experiences had a rate of $8.1 \%$. Furthermore, men who reported prepubescent sexual experiences had sexual reoffending rate of $21.2 \%$, whereas men who did not report such experiences had a rate of $7.2 \%$. Mean onset of masturbation of recidivists was $M=12.63$ years, whereas mean onset of masturbation of non-recidivists was $M=13.70$. Effect sizes of the measures' correlations with sexual recidivism are shown in Table 6. The Area Under the Curve (AUC) value can be interpreted as the probability that a randomly selected recidivist will have a higher score on the according risk variable than a randomly selected non-recidivist (Seto, 2005).

Table 6

Prediction of Sexual Recidivism by Sexual Biography, Pedosexual Interests, and Static-99

\begin{tabular}{|c|c|c|c|c|c|}
\hline \multirow[b]{2}{*}{ Predictor } & \multirow[b]{2}{*}{$n$} & \multicolumn{2}{|c|}{ ROC analyses } & \multicolumn{2}{|c|}{ Correlation coefficient } \\
\hline & & AUC & $95 \% \mathrm{CI}$ & $r$ & $p$ \\
\hline \multicolumn{6}{|l|}{ Sexual biography } \\
\hline Own sexually abusive experiences ${ }^{a}$ & 195 & .61 & {$[.47, .74]$} & $.15^{\mathrm{c}}$ & .034 \\
\hline Prepubescent sexual experiences ${ }^{a}$ & 190 & .64 & {$[.51, .77]$} & $.20^{\mathrm{c}}$ & .006 \\
\hline Onset of masturbation (in years) & 141 & .62 & {$[.46, .78]$} & $-.15^{\mathrm{c}}$ & .086 \\
\hline Frequency of masturbation ${ }^{b}$ & 122 & .68 & {$[.52, .84]$} & $.21^{\mathrm{d}}$ & .020 \\
\hline Sexual biographical index & 97 & .74 & {$[.59, .88]$} & $.30^{\mathrm{c}}$ & .003 \\
\hline \multicolumn{6}{|l|}{ Pedosexual interests } \\
\hline Pedophilic disorder & 198 & .68 & {$[.54, .81]$} & $.19^{\mathrm{d}}$ & .006 \\
\hline SSPI & 202 & .69 & {$[.58, .81]$} & $.22^{\mathrm{c}}$ & .002 \\
\hline Static-99 & 200 & .81 & {$[.71, .92]$} & $.40^{\mathrm{c}}$ & $<.001$ \\
\hline
\end{tabular}

Note. ROC = Receiver Operating Characteristic; AUC = Area under the Curve; $\mathrm{CI}=$ Confidence interval; Sexual biographical index = Accumulation of early sexual behavior and (abusive or non-abusive) experiences; Pedophilic disorder ( 0 = no disorder, 1 = non-exclusive disorder, 2 = exclusive disorder $)$;SPI = Screening Scale of Pedophilic Interests (Seto \& Lalumière, 2001).

${ }^{\mathrm{a}} 0=$ absent, $1=$ present ${ }^{\mathrm{b}} 0=$ never (or very seldom), $1=$ occasionally (now and then up to $1-2 x /$ week), $2=$ regularly (at least $2 x /$ week), or 3 = daily. 'Pearson's correlation coefficient. 'Spearman's rank correlation coefficient.

There were significant bivariate correlations between own sexually abusive experiences, non-abusive prepubescent sexual experiences, onset of masturbation, frequency of mas- 
turbation (during puberty) and the biographical index on the one hand and recidivism on the other hand. All correlations can be classified as small (Cohen, 1988), except for the biographical index which was moderately linked to officially registered recidivism.

The predictions in terms of AUC are mostly but not completely in line with the correlation analyses. They indicate moderate links between non-abusive prepubescent sexual experiences and frequency of masturbation (during puberty) on the one hand and sexual recidivism on the other hand, whereas the AUC of sexual biographical index values indicates a strong effect (Rice \& Harris, 2005). The AUC values of onset of masturbation and own sexually abusive experiences did not reach the level of significance as their confidence intervals were located around .50 .

Further pairwise comparisons revealed that exclusively pedophilic men had a significantly higher rate of reconvictions because of sexual offenses than men without a pedophilic disorder diagnosis $(27.3 \%$ vs. $4.9 \%), \chi^{2}(1)=11.20, p=.001, \Phi=.30$, while no other group difference was significant.

In a further step, it was examined if the sexual biographical index incrementally added to the predictive accuracy of a well-established risk assessment tool (i.e., the Static-99; Hanson \& Thornton, 1999, 2000). A Cox regression analysis was conducted for this purpose. First, the bivariate relationship of the two predictors of interest were examined. There was a small correlation $(r=.23, p=.023)$ between the biographical index and the Static-99 total values. For better interpretability of the Cox regression statistics, both measures were $z$-standardized. Static-99 scores were entered into the model in the first step, and the sexual biographical index values were entered in the second step. Results of the analysis are shown in Table 7 . The $\chi^{2}$-statistics of step 2 show that entering sexual biographical index values into the prediction model did not increase the prediction accuracy significantly. Thus, the sexual biographical index did not incrementally add predictive power beyond what was captured by the Static-99 for the prediction of sexual recidivism.

\section{Table 7}

Incremental Contribution of the Sexual Biographical Index Beyond the Static-99 for the Prediction of Sexual Recidivism Using Cox Regression Analyses ( $n=97)$

\begin{tabular}{|c|c|c|c|c|c|c|c|c|c|}
\hline \multirow[b]{2}{*}{ Predictor } & \multicolumn{3}{|c|}{$\chi^{2}$ change } & \multicolumn{4}{|c|}{ Regression coefficients } & \multicolumn{2}{|c|}{ Rate ratio } \\
\hline & change & $d f$ & $p$ & $b$ & $S E$ & Wald & $p$ & $\operatorname{Exp}(b)$ & 95\% CI \\
\hline \multicolumn{10}{|l|}{ Step 1} \\
\hline Static-99 & 26.00 & 1 & $<.001$ & 1.18 & 0.25 & 22.88 & $<.001$ & 3.26 & {$[2.01,5.29]$} \\
\hline \multicolumn{10}{|l|}{ Step 2} \\
\hline Static-99 & & & & 1.11 & 0.26 & 18.41 & $<.001$ & 3.02 & {$[1.82,5.00]$} \\
\hline Sexual biographical index & 1.53 & 1 & .216 & 0.32 & 0.26 & 1.48 & .227 & 1.38 & {$[0.82,2.31]$} \\
\hline
\end{tabular}

Note. $\mathrm{CI}=$ Confidence interval. Sexual biographical index = accumulation of early sexual behavior and (abusive or non-abusive) experiences. Total: $\chi^{2}(2)=37.46, p<.001$. 


\section{Discussion}

The present study provides further insights into the development of pedosexual interests by replicating findings concerning the link between own sexually abusive experiences during childhood and subsequent pedosexual interests among adult men who have committed CSA-related offenses (e.g., Becker et al., 1992; Fedoroff \& Pinkus, 1996; Nunes et al., 2013). Furthermore, it was examined whether other sexual biographical characteristics could predict pedosexual interests. It was expected that non-abusive sexual experiences and behaviors would be linked to a sexual interest in children, and that the link would be even stronger in the case of an exclusive pedophilic disorder.

The results of the present study support previous findings concerning the increased rate of own sexually abusive experience during childhood within men with indicators of pedosexual interests compared to men without such indicators. First and in line with the hypotheses, there was a significant link between own sexually abusive experiences and subsequent pedosexual interests. The rate of own sexually abusive experiences among those participants with an exclusive pedophilic disorder was about three times higher than in the case of those men without a referring disorder: Almost half of that group reported such experiences during their childhood. This trend was also present when tested for the SSPI scores in that they were linked to the self-reported rate of own sexually abusive experiences.

Social learning mechanisms could partly explain this finding in that some of the sexually abused persons anticipate the sexual arousal of their perpetrator. Pedosexual interests following sexual victimization in childhood could in some cases also be a result of dysfunctional emotion regulation efforts, so that sexually abusive experiences are rationalized in the purpose of overcoming the own victimization and therefore sex with children becomes an acceptable fantasy. But it still remains unclear why only some of those who experience sexual abuse develop pedosexual interests. One possible explanation could be potential interaction effects with other predisposing effects like neuropsychological vulnerabilities (e.g., Turner \& Rettenberger, 2020).

Analyzes of potential links between other forms of childhood sexual experiences and indicators of pedosexual interests were tested based on the assumption that social learning and conditioning mechanisms can also increase the risk of developing pedosexual interests in case of non-abusive childhood sexual experiences. Referring analyses revealed significant and hypothesis-confirming associations between prepubescent non-abusive sexual experiences and pedosexual interests during adulthood. In line with the results concerning the relationship between own sexually abusive experiences and pedosexual interests, those participants who were diagnosed with an exclusive pedophilic disorder showed the highest rate of prepubescent sexual experiences: more than half of that group reported to have had sexual experiences during childhood which they did not categorize as abusive. Additionally, there was a positive link between the SSPI scores and the rate of self-reported prepubescent non-abusive sexual experiences. One possible underlying 
mechanism might be that cues of the sexual interactions with other children, i.e. childish physical cues, are paired with sexual arousal, and in some cases-if those experiences become a masturbatory fantasy-the association between those childish cues and sexual arousal could persist. Those results are in line with previous findings indicating that conditioning is a possible determinant of sexual age preferences (Santtila et al., 2010; Seto, 2018).

It is noteworthy, that most of the reported prepubescent sexual experiences were some kind of "doctor games" which are also seen as normal behavior in sexual development of children (e.g., Fitzpatrick et al., 1995; Lamb \& Coakley, 1993; Larsson et al., 2000); and as the majority of children who show sexual play behavior do not become pedophilic later in life, other factors are necessary to develop such sexual preferences. However, although sexual interactions between children seem to be quite common in children between the ages of 3 and 6 years (Wurtele \& Kenny, 2011) and should therefore not be interpreted as a risk factor for a paraphilic disorder or sexual offending in general, such interactions seem to be of diagnostic and prognostic relevance in a subgroup of sexually offending men.

Concerning the onset and the frequency of masturbation, the results of the present study were not consistent. Against the hypothesized pattern, both masturbation variables were not significantly linked to a pedophilic disorder. In contrast, both masturbation variables were linked to SSPI scores in the expected way: The earlier a person had begun to masturbate and the more frequently he had masturbated during puberty, the higher his SSPI score was. Those latter results are in line with findings indicating an increased sex drive among men sexually attracted to children (Dawson et al., 2016; Wurtele et al., 2018). The link between primarily behavioral indicators of pedophilic sexual interests (i.e., SSPI scores) on the one hand and indicators of an increased sex drive on the other hand could possibly be explained by a joint tendency towards sensation seeking or impulsivity to some extent. In line with that, it has been suggested that a person's risk to show paraphilic behavior (which should not be confused with a paraphilic preference) may be influenced by his or her level of impulsivity (e.g., Lalumière et al., 2005). Besides sex drive, also other indirect measures of impulsivity (e.g., consumption of alcohol and other illegal drugs) were shown to be linked to engaging in paraphilic behaviors (Långström \& Seto, 2006). However, other findings indicated that sexual impulsivity is a separate construct and should be differentiated from general impulsivity (Rettenberger et al., 2016; Turner et al., 2018).

When the sexual biographical index (accumulation of early sexual behavior and experiences) was used, the hypothesized associations were largely confirmed. There was a positive correlation between the biographical index and both measures of pedosexual interests. This finding indicates that an accumulation of sexual experiences and behaviors at an early stage of life is to some extent predictive for subsequent pedosexual interests, at least among men who have sexually offended against children. 
Apart from that and in line with previous research (e.g., McPhail et al., 2018), the results also indicate that exclusively pedophilic men seem to constitute a diagnostically as well as prognostically distinct group within the population of individuals convicted of CSA-related offenses. Their sexual experiences and behaviors during and before puberty seem to differ more from non-pedophilic individuals than in the case of men diagnosed as having a non-exclusively pedophilic disorder, as they showed the strongest accumulation of early sexual behavior and experiences. It is quite plausible that being solely sexually attracted to children rather than being also attracted to persons of the same age is linked to sexual experiences that do differ in a stronger way from those made by people without pedophilic sexual interests at all as non-exclusively pedophilic sexual interests include by definition normative sexual preferences and behaviors. Therefore, exclusively pedosexual interests might become apparent earlier in the sexual biography of a person. This interpretation of the current study's findings is in line with existing evidence regarding the onset of pedosexual interests. Recently, Tozdan and Briken (2019), for example, found that the earlier a sexual attraction to children was present in participants, the more likely they were exclusively attracted to children. The relevance and distinctiveness of the exclusivity of pedosexual interests is also supported by the analyses concerning sexual recidivism in that the respective group had the highest rate of sexual reoffending, which is in line with findings of previous studies (Beier, 1998; Eher et al., 2010, 2015; McPhail et al., 2018).

Besides their links to pedosexual interests, the prognostic relevance of the sexual biographical characteristics was investigated. Thereby, the found relationship between sexually abusive experiences during childhood and sexual recidivism extends the existing body of research regarding the abused-abuser hypothesis (e.g., Garland \& Dougher, 1990; Marshall \& Marshall, 2016; Seto, 2008). Regarding the influence of own sexually abusive experiences on recidivism risk (in contrast to initial sexual offending), previous studies have reported inconsistent findings so far. While Hanson and Bussière (1998) did not find a substantial link between own sexually abusive experiences and sexual reoffending, Mallie and colleagues (2011) reported a weak but statistically significant relationship $(O R=1.5, p=.02)$ when taking findings of nine studies on adolescent offenders into account.

The found relationship between the frequency of masturbation during puberty and sexual recidivism is in accordance with studies that identified hypersexuality as a risk factor of sexual reoffending (Etzler et al., 2020; Hanson \& Morton-Bourgon, 2005; Kingston \& Bradford, 2013), whereas the onset of masturbation in general showed the weakest associations with the outcome measures compared to the other sexual biographical characteristics. The frequency of masturbation might be a more appropriate measure of a high sex drive than the onset of masturbation since the latter might be strongly confounded by the natural variance in physical maturation and therefore might not be that meaningful in the emergence of deviant sexual preferences and behaviors. 
The sexual biographical index significantly predicted sexual recidivism, at least when no further information was taken into account, i.e., an accumulation of including abusive as well as non-abusive early sexual experiences and behaviors is of prognostic relevance concerning sexual recidivism among individuals convicted of CSA-related offenses. However, further analyses revealed that the investigated sexual biographical information, represented by the sexual biographical index, did not incrementally add predictive power beyond that captured by the Static-99 concerning the prediction of sexual recidivism. This result could partly be explained by the joint variance of the sexual biographical index values and the Static-99 scores as there was a weak but statistically significant correlation between the two measures. Additionally, the index variable had a low sample size (see below) and incremental analyses are particularly low in statistical power. Furthermore, the findings could be interpreted as a further evidence of the validity of the Static-99.

\section{Limitations and Future Studies}

Our results are limited because of missing data. The missing data proportion was particularly high regarding the independent variables, i.e., the sexual biographical data. One reason might be that those variables were not the main focus of the forensic reports at the FECVSO, and thus, they were not documented in such detail as if a separate data collection had been performed. Furthermore, information about childhood sexual experiences and behaviors was assessed retrospectively and via self-report. The information of interest affected experiences a long time ago, in some cases several decades. Some men might just have been unable to remember the information they were asked for. Especially memories concerning the time before puberty is prone to be affected by a reminiscence bump, i.e. the tendency for adults to remember primarily autobiographical events that occurred during adolescence and early adulthood (Conway \& Haque, 1999; Jansari \& Parkin, 1996).

Because of the limited information available in the forensic reports of the FECVSO we had to code non-abusive prepubescent sexual experiences dichotomously. It is plausible, though, that participants with pedosexual interests, especially the exclusive type, do not only differ regarding the presence or absence of such experiences in general but also regarding their quantity and quality of sexual play during childhood compared to offenders without pedosexual interests. Thus, investigating different kinds of prepubescent sexual experiences in men with pedosexual interests and their potential interactions should be an aim of future studies. However, such intentions would require larger samples of men who have provided a detailed sexual history. In order to identify causal links between biographical factors and pedophilic sexual interests, it would also be conceivable to take specific chronological orders of the biographical characteristics into account, for example, whether sexually abusive experiences occurred before non-abusive sexual experiences or vice versa. 
Furthermore, in the current study we included only men who were convicted because of a previous sexual offense and thus our results cannot be generalized to men with pedosexual interests who have not sexually offended. It can be assumed that the former group holds many confounding variables such as a lower impulse control (Gunst et al., 2017; Turner et al., 2018) or a higher tendency towards psychopathy (Porter et al., 2000) which could have influenced the results. In this context, it would be interesting to investigate whether pedosexual interests are only linked to an increased sex drive in samples of men who have already sexually offended. It is conceivable that a low sex drive could be a protective factor in men with pedosexual interests in that they are more likely to desist from offending.

Finally, while several studies conceptualize pedosexual interests as two-ordered, i.e. pedophilic versus not-pedophilic (e.g., Fedoroff \& Pinkus, 1996; Fromberger et al., 2012; Lee et al., 2002; Wurtele et al., 2014), the above mentioned findings concerning individuals diagnosed as exclusively pedophilic suggest that future studies on precursors of sexual interest in children and of sexual offending should assess pedosexual interests more differentiated by taking the distinction between exclusively and non-exclusively pedophilic men into account.

\section{Conclusions}

The current study extends the existing research regarding the role of social learning-in the form of childhood sexual experiences and behavior-in the etiology of pedosexual interests. The results revealed that an accumulation of abusive and non-abusive sexual biographical characteristics could increase the risk of developing an (exclusive) pedosexual interest in men who have been convicted for a previous sexual offense against children. Furthermore, sexual biographical information seems to be linked to sexual recidivism, at least to some extent, even though it failed to add incremental predictive power beyond actuarial risk assessment. Despite the methodical limitations, the results account for the diagnostic and prognostic relevance of sexual biographical information in the course of the assessment of individuals convicted of CSA-related offenses. 
Funding: The authors have no funding to report.

Competing Interests: The second author (MR) is one of SOTRAP's Editors-in-Chief, but played no editorial role for this particular article or intervened in any form in the peer review procedure.

Acknowledgments: The authors have no support to report.

Author Note: The current research project was conducted in accordance with the legal and ethical demands of the Austrian Department of Justice and in accordance with the national Data Protection Act. The views expressed are those of the authors and not necessarily those of the Austrian Prison System.

Data Availability: The data used for the present study is the property of the Austrian Department of Justice. Therefore, we are not able to make the data publicly available; however, the data of the present study could be made available upon request to the corresponding author.

\section{Supplementary Materials}

We provide the IBM SPSS syntax (version 23) for our data analyses (for access see Index of Supplementary Materials below). It can be applied to the study data which could be made available upon request to the corresponding author.

\section{Index of Supplementary Materials}

Breiling, L., Rettenberger, M., \& Turner, D. (2020). Supplementary materials to "The relevance of sexual biographies in individuals convicted of child sexual abuse offenses for the development of pedosexual interests and sexual recidivism" [SPSS syntax]. PsychOpen.

https://doi.org/10.23668/psycharchives.3083

\section{References}

Ahlers, C. J., Schaefer, G. A., Mundt, I. A., Roll, S., Englert, H., Willich, S. N., \& Beier, K. M. (2011). How unusual are the contents of paraphilias? Paraphilia-associated sexual arousal patterns in a community-based sample of men. fournal of Sexual Medicine, 8(5), 1362-1370. https://doi.org/10.1111/j.1743-6109.2009.01597.x

American Psychiatric Association. (2000). DSM-IV-TR: Diagnostic and statistical manual of mental disorders-Text revision. Arlington, VA, USA: American Psychiatric Association.

American Psychiatric Association. (2013). Diagnostic and statistical manual of mental disorders: DSM-5 (5th ed.). Washington, DC, USA: American Psychiatric Publishing.

Baumeister, R. F., Catanese, K. R., \& Vohs, K. D. (2001). Is there a gender difference in strength of sex drive? Theoretical views, conceptual distinctions, and a review of relevant evidence. 
Personality and Social Psychology Review, 5(3), 242-273.

https://doi.org/10.1207/S15327957PSPR0503_5

Baur, E., Forsman, M., Santtila, P., Johansson, A., Sandnabba, K., \& Långström, N. (2016). Paraphilic sexual interests and sexually coercive behavior: A population-based twin study. Archives of Sexual Behavior, 45(5), 1163-1172. https://doi.org/10.1007/s10508-015-0674-2

Becker, J. V., Kaplan, M. S., \& Tenke, C. E. (1992). The relationship of abuse history, denial and erectile response profiles of adolescent sexual perpetrators. Behavior Therapy, 23(1), 87-97. https://doi.org/10.1016/S0005-7894(05)80310-7

Beier, K. M. (1998). Differential typology and prognosis for dissexual behavior-A follow-up study of previously expert-appraised child molesters. International fournal of Legal Medicine, 111(3), 133-141. https://doi.org/10.1007/s004140050133

Blanchard, R., Kolla, N. J., Cantor, J. M., Klassen, P. E., Dickey, R., Kuban, M. E., \& Blak, T. (2007). IQ, handedness, and pedophilia in adult male patients stratified by referral source. Sexual Abuse, 19(3), 285-309. https://doi.org/10.1177/107906320701900307

Burton, D. L. (2003). Male adolescents: Sexual victimization and subsequent sexual abuse. Child \& Adolescent Social Work fournal, 20(4), 277-296. https://doi.org/10.1023/A:1024556909087

Cantor, J. M., Kabani, N., Christensen, B. K., Zipursky, R. B., Barbaree, H. E., Dickey, R., . . . Blanchard, R. (2008). Cerebral white matter deficiencies in pedophilic men. fournal of Psychiatric Research, 42(3), 167-183. https://doi.org/10.1016/j.jpsychires.2007.10.013

Castellini, G., Rellini, A. H., Appignanesi, C., Pinucci, I., Fattorini, M., Grano, E., . . Ricca, V. (2018). Deviance or normalcy? The relationship among paraphilic thoughts and behaviors, hypersexuality, and psychopathology in a sample of university students. Fournal of Sexual Medicine, 15(9), 1322-1335. https://doi.org/10.1016/j.jsxm.2018.07.015

Cohen, J. (1988). Statistical power analysis for the behavioral sciences (2nd ed.). Hoboken, NJ, USA: Taylor and Francis.

Conway, M. A., \& Haque, S. (1999). Overshadowing the reminiscence bump: Memories of a struggle for independence. fournal of Adult Development, 6(1), 35-44. https://doi.org/10.1023/A:1021672208155

Craissati, J., McClurg, G., \& Browne, K. (2002). Characteristics of perpetrators of child sexual abuse who have been sexually victimized as children. Sexual Abuse, 14(3), 225-239. https://doi.org/10.1177/107906320201400303

Dawson, S. J., Bannerman, B. A., \& Lalumière, M. L. (2016). Paraphilic interests: An examination of sex differences in a nonclinical sample. Sexual Abuse, 28(1), 20-45. https://doi.org/10.1177/1079063214525645

Dombert, B., Schmidt, A. F., Banse, R., Briken, P., Hoyer, J., Neutze, J., \& Osterheider, M. (2016). How common is men's self-reported sexual interest in prepubescent children? fournal of Sex Research, 53(2), 214-223. https://doi.org/10.1080/00224499.2015.1020108

Ducro, C., \& Pham, T. (2006). Evaluation of the SORAG and the Static-99 on Belgian sex offenders committed to a forensic facility. Sexual Abuse, 18(1), 15-26.

https://doi.org/10.1177/107906320601800102 
Eher, R. (2016). The forensic relevance of paedophilia in the assessment of child molesters. In L. A. Craig, M. Rettenberger, \& D. P. Boer (Eds.), The Wiley handbook on the theories, assessment, and treatment of sexual offending: Volume 2. Assessment (pp. 863-875). Chichester, United Kingdom: Wiley-Blackwell. https://doi.org/10.1002/9781118574003

Eher, R., Matthes, A., Schilling, F., Haubner-Maclean, T., \& Rettenberger, M. (2012). Dynamic risk assessment in sexual offenders using STABLE-2000 and the STABLE-2007: An investigation of predictive and incremental validity. Sexual Abuse, 24(1), 5-28.

https://doi.org/10.1177/1079063211403164

Eher, R., Olver, M. E., Heurix, I., Schilling, F., \& Rettenberger, M. (2015). Predicting reoffense in pedophilic child molesters by clinical diagnoses and risk assessment. Law and Human Behavior, 39(6), 571-580. https://doi.org/10.1037/lhb0000144

Eher, R., Rettenberger, M., Matthes, A., \& Schilling, F. (2010). Stable dynamic risk factors in child sexual abusers: The incremental predictive power of narcissistic personality traits beyond the Static-99/Stable-2007 priority categories on sexual reoffense. Sexual Offender Treatment, 5(1), 1-12. Retrieved from http://www.sexual-offender-treatment.org/2-2010_02.html

Eher, R., Rettenberger, M., \& Turner, D. (2019). The prevalence of mental disorders in incarcerated contact sexual offenders. Acta Psychiatrica Scandinavica, 139(6), 572-581. https://doi.org/10.1111/acps.13024

Etzler, S., Eher, R., \& Rettenberger, M. (2020). Dynamic risk assessment of sexual offenders: Validity and dimensional structure of the Stable-2007. Assessment, 27(4), 822-839. https://doi.org/10.1177/1073191118754705

Fedoroff, J. P., \& Pinkus, S. (1996). The genesis of pedophilia: Testing the "abuse-to-abuser" hypothesis. Journal of Offender Rehabilitation, 23(3-4), 85-101.

https://doi.org/10.1300/J076v23n03_06

Fitzpatrick, C., Deehan, A., \& Jennings, S. (1995). Children's sexual behaviour and knowledge: A community study. Irish fournal of Psychological Medicine, 12(3), 87-91. https://doi.org/10.1017/S079096670001449X

Fleiss, J. L. (1986). The design and analysis of clinical experiments. New York, NY, USA: Wiley.

Freund, K., Watson, R. J., \& Dickey, R. (1990). Does sexual abuse in childhood cause pedophilia: An exploratory study. Archives of Sexual Behavior, 19(6), 557-568. https://doi.org/10.1007/BF01542465

Fromberger, P., Jordan, K., Steinkrauss, H., von Herder, J., Witzel, J., Stolpmann, G., . . Müller, J. L. (2012). Diagnostic accuracy of eye movements in assessing pedophilia. fournal of Sexual Medicine, 9(7), 1868-1882. https://doi.org/10.1111/j.1743-6109.2012.02754.x

Garland, R. J., \& Dougher, M. J. (1990). The abused/abuser hypothesis of child sexual abuse: A critical review of theory and research. In J. R. Feierman (Ed.), Pedophilia: Biosocial dimensions (pp. 488-509). New York, NY, USA: Springer New York. https://doi.org/10.1007/978-1-4613-9682-6_20

Gunst, E., Watson, J. C., Desmet, M., \& Willemsen, J. (2017). Affect regulation as a factor in sex offenders. Aggression and Violent Behavior, 37, 210-219. https://doi.org/10.1016/j.avb.2017.10.007 
Hanson, R. K., \& Bussière, M. T. (1998). Predicting relapse: A meta-analysis of sexual offender recidivism studies. fournal of Consulting and Clinical Psychology, 66(2), 348-362. https://doi.org/10.1037/0022-006X.66.2.348

Hanson, R. K., \& Morton-Bourgon, K. E. (2004). Predictors of sexual recidivism: An updated metaanalysis (Corrections User Report No. 2004-02). Ottawa, ON, Canada: Public Safety Canada.

Hanson, R. K., \& Morton-Bourgon, K. E. (2005). The characteristics of persistent sexual offenders: A meta-analysis of recidivism studies. Journal of Consulting and Clinical Psychology, 73(6), 1154-1163. https://doi.org/10.1037/0022-006X.73.6.1154

Hanson, R. K., \& Thornton, D. (1999). Static 99: Improving actuarial risk assessments for sex offenders (User Report No. 1999-02). Retrieved from https://www.publicsafety.gc.ca/cnt/rsrcs/pblctns/sttc-mprvng-actrl/sttc-mprvng-actrl-eng.pdf

Hanson, R. K., \& Thornton, D. (2000). Improving risk assessments for sex offenders: A comparison of three actuarial scales. Law and Human Behavior, 24(1), 119-136.

https://doi.org/10.1023/A:1005482921333

Helmus, L., Ó Ciardha, C., \& Seto, M. C. (2015). The Screening Scale for Pedophilic Interests (SSPI): Construct, predictive, and incremental validity. Law and Human Behavior, 39(1), 35-43. https://doi.org/10.1037/lhb0000099

Helmus, L., Thornton, D., Hanson, R. K., \& Babchishin, K. M. (2012). Improving the predictive accuracy of Static-99 and Static-2002 with older sex offenders: Revised age weights. Sexual Abuse, 24(1), 64-101. https://doi.org/10.1177/1079063211409951

Hunter, J. A., Jr., \& Becker, J. V. (1994). The role of deviant sexual arousal in juvenile sexual offending: Etiology, evaluation, and treatment. Criminal fustice and Behavior, 21(1), 132-149. https://doi.org/10.1177/0093854894021001009

Jansari, A., \& Parkin, A. J. (1996). Things that go bump in your life: Explaining the reminiscence bump in autobiographical memory. Psychology and Aging, 11(1), 85-91.

https://doi.org/10.1037/0882-7974.11.1.85

Jespersen, A. F., Lalumière, M. L., \& Seto, M. C. (2009). Sexual abuse history among adult sex offenders and non-sex offenders: A meta-analysis. Child Abuse \& Neglect, 33(3), 179-192. https://doi.org/10.1016/j.chiabu.2008.07.004

Joyal, C. C., \& Carpentier, J. (2017). The prevalence of paraphilic interests and behaviors in the general population: A provincial survey. fournal of Sex Research, 54(2), 161-171. https://doi.org/10.1080/00224499.2016.1139034

Kafka, M. P. (2001). The paraphilia-related disorders: A proposal for a unified classification of nonparaphilic hypersexuality disorders. Sexual Addiction \& Compulsivity, 8(3-4), 227-239. https://doi.org/10.1080/107201601753459937

Kingston, D. A., \& Bradford, J. M. (2013). Hypersexuality and recidivism among sexual offenders. Sexual Addiction \& Compulsivity, 20, 91-105. https://doi.org/10.1080/10720162.2013.768131

Klein, V., Schmidt, A. F., Turner, D., \& Briken, P. (2015). Are sex drive and hypersexuality associated with pedophilic interest and child sexual abuse in a male community sample? PLoS One, 10(7), Article e0129730. https://doi.org/10.1371/journal.pone.0129730 
Lalumière, M. L., Harris, G. T., Quinsey, V. L., \& Rice, M. E. (2005). The causes of rape: Understanding individual differences in male propensity for sexual aggression. Washington, DC, USA: American Psychological Association. https://doi.org/10.1037/10961-000

Lamb, S., \& Coakley, M. (1993). "Normal" childhood sexual play and games: Differentiating play from abuse. Child Abuse \& Neglect, 17(4), 515-526. https://doi.org/10.1016/0145-2134(93)90026-2

Långström, N., \& Seto, M. C. (2006). Exhibitionistic and voyeuristic behavior in a Swedish national population survey. Archives of Sexual Behavior, 35(4), 427-435.

https://doi.org/10.1007/s10508-006-9042-6

Larsson, I., Svedin, C.-G., \& Friedrich, W. N. (2000). Differences and similarities in sexual behaviour among pre-schoolers in Sweden and USA. Nordic fournal of Psychiatry, 54(4), 251-257. https://doi.org/10.1080/080394800448110

Laws, D. R., \& Marshall, W. L. (1990). A conditioning theory of the etiology and maintenance of deviant sexual preferences and behavior. In W. L. Marshall, H. E. Barbaree, \& D. R. Laws (Eds.), Applied clinical psychology: Handbook of sexual assault: Issues, theories, and treatment of the offender (pp. 209-229). Boston, MA, USA: Springer US.

Lee, J. K. P., Jackson, H. J., Pattison, P., \& Ward, T. (2002). Developmental risk factors for sexual offending. Child Abuse \& Neglect, 26(1), 73-92. https://doi.org/10.1016/S0145-2134(01)00304-0

Mallie, A. L., Viljoen, J. L., Mordell, S., Spice, A., \& Roesch, R. (2011). Childhood abuse and adolescent sexual re-offending: A meta-analysis. Child and Youth Care Forum, 40(5), 401-417. https://doi.org/10.1007/s10566-010-9136-0

Marshall, W. L., \& Barbaree, H. E. (1990). An integrated theory of the etiology of sexual offending. In W. L. Marshall, H. E. Barbaree, \& D. R. Laws (Eds.), Applied clinical psychology: Handbook of sexual assault: Issues, theories, and treatment of the offender (pp. 257-275). Boston, MA, USA: Springer US.

Marshall, W. L., \& Marshall, L. E. (2016). The origins of sexual offending. Trauma, Violence \& Abuse, 1(3), 250-263. https://doi.org/10.1177/1524838000001003003

McPhail, I. V., Olver, M. E., Brouillette-Alarie, S., \& Looman, J. (2018). Taxometric analysis of the latent structure of pedophilic interest. Archives of Sexual Behavior, 47, 2223-2240. https://doi.org/10.1007/s10508-018-1225-4

Nagelkerke, N. J. D. (1991). A note on a general definition of the coefficient of determination. Biometrika, 78(3), 691-692. https://doi.org/10.1093/biomet/78.3.691

Nunes, K. L., Hermann, C. A., Malcom, J. R., \& Lavoie, K. (2013). Childhood sexual victimization, pedophilic interest, and sexual recidivism. Child Abuse \& Neglect, 37(9), 703-711. https://doi.org/10.1016/j.chiabu.2013.01.008

Porter, S., Fairweather, D., Drugge, J., Hervé, H., Birt, A., \& Boes, D. P. (2000). Profiles of psychopathy in incarcerated sexual offenders. Criminal fustice and Behavior, 27(2), 216-233. https://doi.org/10.1177/0093854800027002005

Rettenberger, M., Haubner-Maclean, T., \& Eher, R. (2013). The contribution of age to the Static-99 risk assessment in a population-based prison sample of sexual offenders. Criminal fustice and Behavior, 40(12), 1413-1433. https://doi.org/10.1177/0093854813492518 
Rettenberger, M., Klein, V., \& Briken, P. (2016). The relationship between hypersexual behavior, sexual excitation, sexual inhibition, and personality traits. Archives of Sexual Behavior, 45(1), 219-233. https://doi.org/10.1007/s10508-014-0399-7

Rettenberger, M., Matthes, A., Boer, D. P., \& Eher, R. (2010). Prospective actuarial risk assessment: A comparison of five risk assessment instruments in different sexual offender subtypes. International fournal of Offender Therapy and Comparative Criminology, 54(2), 169-186. https://doi.org/10.1177/0306624X08328755

Rice, M. E., \& Harris, G. T. (2005). Comparing effect sizes in follow-up studies: ROC Area, Cohen's $d$, and $r$. Law and Human Behavior, 29(5), 615-620. https://doi.org/10.1007/s10979-005-6832-7

Santtila, P., Mokros, A., Hartwig, M., Varjonen, M., Jern, P., Witting, K., . . Sandnabba, N. K. (2010). Childhood sexual interactions with other children are associated with lower preferred age of sexual partners including sexual interest in children in adulthood. Psychiatry Research, 175(1-2), 154-159. https://doi.org/10.1016/j.psychres.2008.10.021

Schiltz, K., Witzel, J., Northoff, G., Zierhut, K., Gubka, U., Fellmann, H., . . Bogerts, B. (2007). Brain pathology in pedophilic offenders: Evidence of volume reduction in the right amygdala and related diencephalic structures. Archives of General Psychiatry, 64(6), 737-746. https://doi.org/10.1001/archpsyc.64.6.737

Seto, M. C. (2005). Is more better? Combining actuarial risk scales to predict recidivism among adult sex offenders. Psychological Assessment, 17(2), 156-167. https://doi.org/10.1037/1040-3590.17.2.156

Seto, M. C. (2008). Pedophilia and sexual offending against children: Theory, assessment, and intervention. Washington, DC, USA: American Psychological Association.

Seto, M. C. (2018). Pedophilia and sexual offending against children: Theory, assessment, and intervention (2nd ed.). Washington, DC, USA: American Psychological Association. https://doi.org/10.1037/0000107-000

Seto, M. C., Harris, G. T., Rice, M. E., \& Barbaree, H. E. (2004). The Screening Scale for Pedophilic Interests predicts recidivism among adult sex offenders with child victims. Archives of Sexual Behavior, 33(5), 455-466. https://doi.org/10.1023/B:ASEB.0000037426.55935.9c

Seto, M. C., \& Lalumière, M. L. (2001). A brief screening scale to identify pedophilic interests among child molesters. Sexual Abuse, 13(1), 15-25. https://doi.org/10.1177/107906320101300103

Seto, M. C., \& Lalumière, M. L. (2010). What is so special about male adolescent sexual offending? A review and test of explanations through meta-analysis. Psychological Bulletin, 136(4), 526-575. https://doi.org/10.1037/a0019700

Seto, M. C., Murphy, W. D., Page, J., \& Ennis, L. (2003). Detecting anomalous sexual interests in juvenile sex offenders. Annals of the New York Academy of Sciences, 989, 118-130, [discussion] 144-153. https://doi.org/10.1111/j.1749-6632.2003.tb07298.x

Sjöstedt, G., \& Långström, N. (2001). Actuarial assessment of sex offender recidivism risk: A crossvalidation of the RRASOR and the Static-99 in Sweden. Law and Human Behavior, 25(6), 629-645. https://doi.org/10.1023/A:1012758307983 
Spector, I. P., Carey, M. P., \& Steinberg, L. (1996). The sexual desire inventory: Development, factor structure, and evidence of reliability. Journal of Sex \& Marital Therapy, 22(3), 175-190. https://doi.org/10.1080/00926239608414655

Tozdan, S., \& Briken, P. (2019). Age of onset and it's correlates in men with sexual interest in children. Sexual Medicine, 7(1), 61-71. https://doi.org/10.1016/j.esxm.2018.10.004

Turner, D., Laier, C., Brand, M., Bockshammer, T., Welsch, R., \& Rettenberger, M. (2018). Response inhibition and impulsive decision-making in sexual offenders against children. Fournal of Abnormal Psychology, 127(5), 471-481. https://doi.org/10.1037/abn0000359

Turner, D., \& Rettenberger, M. (2020). Neuropsychological functions in child sexual abusers: A systematic review. Aggression and Violent Behavior. Advance online publication. https://doi.org/10.1016/j.avb.2020.101405

Turner, D., Rettenberger, M., Lohmann, L., Eher, R., \& Briken, P. (2014). Pedophilic sexual interests and psychopathy in child sexual abusers working with children. Child Abuse \& Neglect, 38(2), 326-335. https://doi.org/10.1016/j.chiabu.2013.07.019

Turner, D., Rettenberger, M., Yoon, D., Klein, V., Eher, R., \& Briken, P. (2016). Risk assessment in child sexual abusers working with children. Sexual Abuse, 28(6), 572-596. https://doi.org/10.1177/1079063214564390

Whitaker, D. J., Le, B., Karl Hanson, R., Baker, C. K., McMahon, P. M., Ryan, G., . . Rice, D. D. (2008). Risk factors for the perpetration of child sexual abuse: A review and meta-analysis. Child Abuse \& Neglect, 32(5), 529-548. https://doi.org/10.1016/j.chiabu.2007.08.005

Wurtele, S. K., \& Kenny, M. C. (2011). Normative sexuality development in childhood: Implications for developmental guidance and prevention of childhood sexual abuse. Counseling and Human Development, 43(9), 1-24.

Wurtele, S. K., Simons, D. A., \& Moreno, T. (2014). Sexual interest in children among an online sample of men and women: Prevalence and correlates. Sexual Abuse, 26(6), 546-568. https://doi.org/10.1177/1079063213503688

Wurtele, S. K., Simons, D. A., \& Parker, L. J. (2018). Understanding men's self-reported sexual interest in children. Archives of Sexual Behavior, 47(8), 2255-2264.

https://doi.org/10.1007/s10508-018-1173-z 


\section{Appendix}

Table A

Correlation Coefficients of Sexual Biographical Variables

\begin{tabular}{|c|c|c|c|c|}
\hline Measure & 1 & 2 & 3 & 4 \\
\hline \multirow[t]{2}{*}{ 1. Own sexually abusive experiences ${ }^{a}$} & - & $.16(.021)^{\mathrm{c}}$ & $-.10(.211)^{\mathrm{c}}$ & $.19(.035)^{\mathrm{d}}$ \\
\hline & & $n=206$ & $n=151$ & $n=130$ \\
\hline \multirow[t]{2}{*}{ 2. Non-abusive prepubescent sexual experiences ${ }^{a}$} & & - & $-.28(.004)^{\mathrm{c}}$ & $.19(.035)^{\mathrm{d}}$ \\
\hline & & & $n=149$ & $n=128$ \\
\hline \multirow[t]{2}{*}{ 3. Onset of masturbation (in years) } & & & - & $-.50(<.001)^{\mathrm{d}}$ \\
\hline & & & & $n=109$ \\
\hline 4. Frequency of masturbation ${ }^{b}$ & & & & - \\
\hline
\end{tabular}

Sexual Offending: Theory, Research, and Prevention is the official journal of the International Association for the Treatment of Sexual Offenders (IATSO).

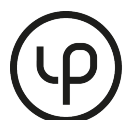

leibniz-psychology.org

PsychOpen GOLD is a publishing service by Leibniz Institute for Psychology Information (ZPID), Germany. 